\title{
A Study on the Interfacial Adhesion Strength of Different Types of Calcium Carbonate Filled Poly (vinyl chloride) Composites
}

\author{
Chuansheng LIU ${ }^{1, a}$, Chengbao WU ${ }^{1, b^{*}}$, Lieshu LIN, c \\ ${ }^{1}$ School of Aircraft Maintenance Engineering, Guangzhou Civil Aviation College, Guangzhou, \\ 510430, China \\ aemail:liuchuansheng@caac.net, bemail:wuchengbao@caac.net, ${ }^{\mathrm{c} e m a i l}$ :linlieshu@caac.net
}

Keywords: Calcium Carbonate, Polyvinyl-chloride, Composite, Mechanical Properties, Adhesion Strength

\begin{abstract}
The Polyvinyl-chloride (PVC) composites filled with micro-Calcium Carbonate $\left(\mathrm{CaCO}_{3}\right)$ submicro- $\mathrm{CaCO}_{3}$, nano- $\mathrm{CaCO}_{3}$ and nano-coating micron $\mathrm{CaCO}_{3}$ powder were prepared by the method of melt blending process. The tensile properties of the $\mathrm{PVC} / \mathrm{CaCO}_{3}$ composites were tested at the room temperature. The interfacial adhesion strength between the $\mathrm{CaCO}_{3}$ particle and the $\mathrm{PVC}$ matrix was measured. The results showed that the tensile properties of the $\mathrm{PVC} / \mathrm{CaCO}_{3}$ composites were better than those of the pure PVC in the most conditions; the mechanical properties of the surface treated $\mathrm{CaCO}_{3}$ filled PVC composites were better than the ones of the non-surface treated $\mathrm{CaCO}_{3}$ filled PVC composites. The mechanical properties of the PVC composites filled with nano-coating micron heavy $\mathrm{CaCO}_{3}$ were better than the ones of the he PVC composites filled with heavy $\mathrm{CaCO}_{3}$; among the four types of $\mathrm{CaCO}_{3}$, the mechanical properties of the PVC composites filled common light $\mathrm{CaCO}_{3}$ and ultra-fine light $\mathrm{CaCO}_{3}$ were relatively better; as the interfacial interaction strength, the strength between the ultra-fine light $\mathrm{CaCO}_{3}$ and the PVC matrix was maximum, the one between the common light $\mathrm{CaCO}_{3}$ and the PVC matrix was minimum, the strength between the nano-coating micron heavy $\mathrm{CaCO}_{3}$ and the matrix was bigger than that between the micron heavy $\mathrm{CaCO}_{3}$ and the matrix, the strength between the $\mathrm{CaCO}_{3}$ after being treated and the matrix was increased.
\end{abstract}

\section{Introduction}

Polyvinyl chloride (PVC) is one of the earliest industrialized production of the plastic varieties, which is widely used in automobiles, home appliances, medical, aviation industry because of excellent mechanical property, corrosion resistance, flame retardant properties, cheap price, and abundant sources of raw materials[1][2]. Its production is less than that of the polyethylene (PE) only, and is the second general plastics in the world. While, the hardness and the impact strength of PVC is not good, it is sensitive to notch, its toughness is low, and the tensile properties cannot meet product requirements. So, its application is limited.

Calcium Carbonate $\left(\mathrm{CaCO}_{3}\right)$ is one of the inorganic fillers widely used in the processing of PVC composites. It can not only reduce the amount of resin and the cost, but also can improve the strength, toughness [3] [4], hardness, elastic modulus [5], size stability of the products, etc. While, the bad interfacial compatibility between the $\mathrm{CaCO}_{3}$ particleand PVC matrix may results that the tensile strength, impact strength and compressive strength of the $\mathrm{PVC} / \mathrm{CaCO}_{3}$ composites decreases[6] and the processing performance becomes worse. Therefore, the $\mathrm{CaCO}_{3}$ surface modification to improve the interfacial adhesion between the particle and the matrix was payed attention widely in recent years[7]. Generally speaking, the interfacial adhesion strength between the modified $\mathrm{CaCO}_{3}$ powder and PVC matrix is much larger than that of the non-modified $\mathrm{CaCO}_{3}$ powder and PVC matrix, and the mechanical properties of composite materials is improved; the interfacial adhesion strength between the micro $\mathrm{CaCO}_{3}$ powder and $\mathrm{PVC}$ matrix is lower, the mechanical properties of the composite materials is also not well, the interfacial adhesion strength between the sub-microCaCO ${ }_{3}$ powder and PVC matrix is improved slightly, and the mechanical properties of the composite material is also improved slightly, the interfacial adhesion strength between the nano-meter $\mathrm{CaCO}_{3}$ powder and PVC matrix is the best due to the tunnel effect and 
surface effect of nano-meter powder, so mechanical properties of the composite material is the best one. But, the nano-meter $\mathrm{CaCO}_{3}$ particles can't easily dispersed uniformly in the PVC matrix during the processing of the composite materials, because the nano-meter $\mathrm{CaCO}_{3}$ particles are easily aggregative. That results two negative hands. On one hand, the filling amount of nano-meter $\mathrm{CaCO}_{3}$ powder in PVC is limited, so the production cost cannot be reduced effectively. On the other hand, even if the filler content is low, the local agglomeration cannot be avoided, so, the mechanical properties of the composites cannot be improved ideally. To solve the problems, the researchers tried to mix nano-meter $\mathrm{CaCO}_{3}$ with the micro $\mathrm{CaCO}_{3}$ powder and filled them into the PVC matrix to disperse the nano-meter $\mathrm{CaCO}_{3}$ particle. But, the results were not idea. In recent years, some references reported a new kind product called the micro and nano-meter $\mathrm{CaCO}_{3}$ composite particle was prepared by generating nano-meterCaCO${ }_{3}$ particles on the surface of the micro $\mathrm{CaCO}_{3}$ by chemical reaction, and payed attention widely.

The objectives in this study are to prepare PVC composites filled with four kind of $\mathrm{CaCO}_{3}$ powder and measure the their tensile properties, including tensile strength, elongation at break, tensile elastic modulus, at the room temperature, to investigate effects of the different kinds of the $\mathrm{CaCO}_{3}$ powder on the tensile properties of the $\mathrm{PVC} \mathrm{CaCO}_{3}$ composites. What is more, the interfacial adhesion strength between the $\mathrm{CaCO}_{3}$ particle and the $\mathrm{PVC}$ matrix will be calculated and analyzed.

\section{Experiment}

Raw Materials. The common light calcium carbonate $\left(\mathrm{P}-\mathrm{CaCO}_{3}\right)$ was prepared by the Powder Engineering Labatory of Tsinghua University. Heavy calcium carbonate $\left(\mathrm{G}-\mathrm{CaCO}_{3}\right)$, with particle size 5000 mesh, was prepared by the Powder Engineering Labatory of Tsinghua University, whose mineral was supplied by Jiangxi Xinyu Henghui Mineral Co. Ltd... Micro and nano-meter $\mathrm{CaCO}_{3}$ Composite particle (MG-CaCO ${ }_{3}$ ), with particle size 5000 mesh, was prepared by the Powder Engineering Labatory of Tsinghua University. Superfine ground calcium carbonate $\left(\mathrm{N}-\mathrm{CaCO}_{3}\right)$, with the settling volume $2.71 \mathrm{~g} / \mathrm{ml}$, was prepared by the Powder Engineering Labatory of Tsinghua University. $\gamma$-Aminopropyl triethoxysilane, with trademark KH550, was supplied by Nanjing Jingwei Chemical Industry Co. Ltd.; PVC, with trademark SG-5 and k value 70, was supplied by Shanghai Chlor-alkali Chemical Industry Co. Ltd.

Apparatus. Electronic balance, with trademark SL-N, was produced by Shanghai Minqiao Precision Scientific Instruments Co. Ltd.; High speed mixing machine, with trademark SHR-10A, was manufactured by Zhangjiagang City Yatong Machinery Co. Ltd...Co-rotating twin screw extruder, with trademark TSE-35A, was manufactured by Nanjing Ruiya Polymer Equipment Co., Ltd...Vacuum oven, with trademark ZK0258, was produced by Shanghai Experiment Instrument Factory Co. Ltd... Numerical control full-automatic injection molding machine, with trademark CJ80NC, was manufactured by Zhendei Plastics Machinery Co. Ltd... Desk universal material testing machines, with trademark 5566, was manufactured by the Instron Co. Ltd...

Preparation. The four different kinds of $\mathrm{CaCO}_{3}$ powder were first blended with $\mathrm{PVC}$ in a high-speed mixer. The filler volume fractions of $\mathrm{P}-\mathrm{CaCO}_{3}, \mathrm{G}-\mathrm{CaCO}_{3}$, and $\mathrm{MG}-\mathrm{CaCO} \mathrm{C}_{3}$ were $50 \%$ respectively, and that of the $\mathrm{N}-\mathrm{CaCO}_{3}$ was $5 \%$. Then, the $\mathrm{PP} / \mathrm{CaCO}_{3}$ blends were extruded in the molten state of the resin by means of the co-rotating twin-screw extruder under temperatures from 170 to $185^{\circ} \mathrm{C}$; the screw rotation was $30 \mathrm{rpm}$, and the screw length-to-diameter ratio was 40/35.6; the die temperature is $180^{\circ} \mathrm{C}$. The feeding of the raw materials was done in the forced mode, and the feeding rate was the screw rotation of $25 \mathrm{rpm}$. Then, the extrudate was granulated to produce the $\mathrm{PVC} / \mathrm{CaCO}_{3}$ composites. These granular composites were dried for $5 \mathrm{~h}$ at $90^{\circ} \mathrm{C}$ in Vacuum oven. Finally, the specimens for tensile testing were molded with a plastics injection machine under temperatures ranging from 190 to $205^{\circ} \mathrm{C}$, with the injection pressure varied from 6 to $8 \mathrm{MPa}$, a holding time of $14 \mathrm{~s}$, and a cooling time of $26 \mathrm{~s}$.

Tensile Property Measurements. The tensile properties of the $\mathrm{PP} / \mathrm{CaCO}_{3}$ composites were measured at room temperature by means of the desk universal materials testing machine. The tests were conducted according to ASTM D 638-91, and the cross-head speed was $50 \mathrm{~mm} / \mathrm{min}$. 


\section{Results and Discussion}

The Tensile Properties of $\mathrm{PVC}_{/} \mathrm{CaCO}_{3}$ Composite. The tensile properties are the basic properties of the plastic and important characteristics for the utilization of materials. The tensile properties of the PVC/CaCO 3 composites are shown in Table 1, 2, 3, and 4.

Table 1 the tensile properties of the $\mathrm{PVC} / \mathrm{P}-\mathrm{CaCO}_{3}$ composites

\begin{tabular}{|c|c|c|c|}
\hline $\begin{array}{ll} & \text { Tensile property } \\
\text { Materials }\end{array}$ & $\sigma / \mathrm{MPa}$ & $\delta / \%$ & $E / \mathrm{MPa}$ \\
\hline Pure PVC & 37.07 & 3.98 & 2568.94 \\
\hline $\begin{array}{l}\mathrm{PVC} / \mathrm{CaCO}_{3} \text { composite filled with } \\
\text { modified } \mathrm{P}-\mathrm{CaCO}_{3}\end{array}$ & 36.49 & 3.38 & 1659.97 \\
\hline $\begin{array}{l}\mathrm{PVC} / \mathrm{CaCO}_{3} \text { composite filled with } \\
\text { non-modified } \mathrm{P}-\mathrm{CaCO}_{3}\end{array}$ & 39.69 & 4.45 & 3536.27 \\
\hline \multicolumn{4}{|c|}{ Table 2 the tensile properties of the PVC/G-CaCO ${ }_{3}$ composites } \\
\hline $\begin{array}{ll}\text { Materials } & \text { Tensile property } \\
\end{array}$ & $\sigma / \mathrm{MPa}$ & $\delta / \%$ & E/ MPa \\
\hline Pure PVC & 37.07 & 3.98 & 2568.94 \\
\hline $\begin{array}{l}\mathrm{PVC} / \mathrm{CaCO}_{3} \text { composite filled with } \\
\text { modified G-CaCO3 }\end{array}$ & 39.23 & 2.53 & 2882.11 \\
\hline $\begin{array}{l}\mathrm{PVC} / \mathrm{CaCO}_{3} \text { composite filled with } \\
\text { non-modified G-CaCO} 3\end{array}$ & 39.71 & 5.18 & 3494.77 \\
\hline \multicolumn{4}{|c|}{ Table 3 the tensile property of the PVC/NG-CaCO ${ }_{3}$ composites } \\
\hline $\begin{array}{l}\text { Tensile property } \\
\text { Materials }\end{array}$ & $\sigma / \mathrm{MPa}$ & $\delta / \%$ & $E / \mathrm{MPa}$ \\
\hline Pure PVC & 37.07 & 3.98 & 2568.94 \\
\hline \multirow{2}{*}{$\begin{array}{l}\mathrm{PVC} / \mathrm{CaCO}_{3} \quad \mathrm{Composite} \text { filled witl } \\
\text { modified NG-CaCO} 3 \\
\mathrm{PVC} / \mathrm{CaCO}_{3} \quad \mathrm{Composite}_{3} \text { filled witl } \\
\text { non-modified NG-CaCO} 3\end{array}$} & h 39.71 & 2.48 & 3741.20 \\
\hline & 40.16 & 2.32 & 3786.59 \\
\hline \multicolumn{4}{|c|}{ Table 4 the tensile properties of the $\mathrm{PVC} / \mathrm{N}-\mathrm{CaCO}_{3}$ composites } \\
\hline $\begin{array}{l}\text { Tensile property } \\
\text { Materials }\end{array}$ & $\sigma / \mathrm{Pa}$ & $\delta / \%$ & $E / \mathrm{MPa}$ \\
\hline Pure PVC & 37.07 & 3.98 & 2568.94 \\
\hline $\begin{array}{l}\mathrm{PVC} \mathrm{CaCO} \\
\text { modified } \mathrm{N}-\mathrm{CaCO}_{3}\end{array}$ & 39.84 & 3.25 & 2156.21 \\
\hline $\begin{array}{l}\mathrm{PVC} \mathrm{CaCO}_{3} \text { composite filled with } \\
\text { non-modified } \mathrm{N}-\mathrm{CaCO}_{3}\end{array}$ & 41.09 & 11.72 & 2818.73 \\
\hline
\end{tabular}

One can see by comparing Table 1, 2, 3 and 4 that the tensile properties of the $\mathrm{PVC} / \mathrm{CaCO}_{3}$ composite filled with modified $\mathrm{CaCO}_{3}$ is better than that filled with non-modified $\mathrm{CaCO}_{3}$. For the $\mathrm{PVC} / \mathrm{P}-\mathrm{CaCO}_{3}$ composite, the $\sigma$ and $E$ of $\mathrm{PVC} / \mathrm{P}-\mathrm{CaCO}_{3}$ composite filled with modified $\mathrm{P}-\mathrm{CaCO}_{3}$ increase $8.77 \%$ and $113.03 \%$ compared with $\mathrm{PVC} / \mathrm{P}-\mathrm{CaCO}_{3}$ composite filled with non-modified $\mathrm{P}-\mathrm{CaCO}_{3}$, respectively. The $\delta$ of $\mathrm{PVC} / \mathrm{N}-\mathrm{CaCO}_{3}$ composite filled with modified $\mathrm{N}-\mathrm{CaCO}_{3}$ increases 3.61 times compared with the $\mathrm{PVC} / \mathrm{N}-\mathrm{CaCO}_{3}$ composite filled with non-modified $\mathrm{N}-\mathrm{CaCO}_{3}$. This illustrated that the $\mathrm{CaCO}_{3}$ surface treated with the silane coupling agent was beneficial or improving the interfacial adhesion and resulted in an enhancement of the tensile properties of the $\mathrm{PVC} / \mathrm{CaCO}_{3}$ composites. It is the reason that the silane coupling agent might have made the chemical reaction with the $\mathrm{CaCO}_{3}$ surface and PVC matrix to improve the compatibility between the filler and matrix, respectively. Consequently, the dispersion of $\mathrm{CaCO}_{3}$ in the $\mathrm{PVC}$ matrix and the interfacial adhesion between them were improved correspondingly; this resulted in an increase in the tensile properties. Under the modification conditions, $\sigma$ and $\delta$ of the $\mathrm{PVC} / \mathrm{N}-\mathrm{CaCO}_{3}$ composite are largest; the $\mathrm{PVC} / \mathrm{P}-\mathrm{CaCO}_{3}$ has the largest $\mathrm{E}$ among the four different $\mathrm{PVC} / \mathrm{CaCO}_{3}$ composites. Contrastive analyzing the tensile properties of the $\mathrm{PVC} / \mathrm{G}-\mathrm{CaCO}_{3}$ and $\mathrm{PVC} / \mathrm{NG}-\mathrm{CaCO}_{3}$ composites (as the Table 2 and 3 shows), we can find that the $\sigma$ and $\mathrm{E}$ of the PVC/NG-CaCO 3 composite are larger than those of the $\mathrm{PVC} / \mathrm{G}-\mathrm{CaCO}_{3}$ composite. This is the reason that there are sharp edges and corners on the surface of the $\mathrm{G}-\mathrm{CaCO}_{3}$ particle, when mixing in the resin matrix, the sharp edges and corners are not benefit for formation of a good interface layer, and produce 
stress concentration effect inside the material easily, thus affecting the mechanical properties of the composite; when the nano-meter $\mathrm{CaCO}_{3}$ particles generating on the surface the micro $\mathrm{CaCO}_{3}$ particle , sharp edges and corners on the surface of the $\mathrm{G}-\mathrm{CaCO}_{3}$ particle are reduced or eliminated, which is benefit to the improve the interfacial bond strength, so as to improve the material mechanical properties to some degree.

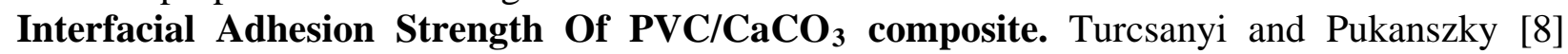
supposed that interfacial adhesion strength is one of important parameters affecting the mechanical properties of the plastic composites, and proposed the interfacial interaction parameter $(B)$ to characterize the interfacial adhesion strength between the surface of the filler particle and the polymer matrix, as the Eq. 1 shows:

$$
B=\frac{1}{\phi_{\mathrm{f}}} \ln \left[\frac{\sigma_{\mathrm{c}}\left(1+2.5 \phi_{\mathrm{f}}\right)}{\sigma_{\mathrm{m}}\left(1-\phi_{\mathrm{f}}\right)}\right]
$$

Where $\phi_{f}$ is volume fraction of the inorganic filler, $\sigma_{\mathrm{c}}$ is tensile strength of the composite, MPa; $\sigma_{\mathrm{m}}$ is the tensile yield strength of the resin, MPa; $B$ is the interfacial interaction parameter, if the interfacial adhesion strength is strong, $B>3$, and the $\sigma_{\mathrm{c}}$ increases with the increasing of $\phi_{f}$. It can be seen from Eq.1 that the Bhas no physical meaning, but it reflections the interface characteristics and depends on the filler volume of the inorganic and the tensile yield strength; the larger the $B$ is, the stronger the interfacial adhesion strength between particle and the matrix.

One can use the calculating program reported in the references[9] [10] to calculate the interfacial reaction parameter of the $\mathrm{PVC} / \mathrm{CaCO}_{3}$ composites, the results are shown in Table 5.

From Table 5, we can see that most $\mathrm{B}$ values of the $\mathrm{PVC} / \mathrm{CaCO}_{3}$ composites are larger than 3 , and the $\mathrm{B}$ of the $\mathrm{PVC} / \mathrm{N}-\mathrm{CaCO}_{3}$ composite is maximum among the four different $\mathrm{PVC} / \mathrm{CaCO}_{3}$ composites; the $\mathrm{B}$ of $\mathrm{PVC} / \mathrm{CaCO}_{3}$ composites filled with modified $\mathrm{CaCO}_{3}$ is larger than the one of the $\mathrm{PVC} / \mathrm{CaCO}_{3}$ composites filled with non-modified $\mathrm{CaCO}_{3}$, for example, the $\mathrm{B}$ of the $\mathrm{PVC} / \mathrm{CaCO}_{3}$ composite filled with modified $\mathrm{N}_{-} \mathrm{CaCO}_{3}$ increases $12.86 \%$ compared with non-modified $\mathrm{N}-\mathrm{CaCO}_{3}$ filled $\mathrm{PVC} / \mathrm{CaCO}_{3}$ composite. That is to say, all of the interfacial adhesion strength between the $\mathrm{CaCO}_{3}$ particle PVC matrix is strong and increase after modified by $\mathrm{CaCO}_{3}$ particles. If comparing the $\mathrm{B}$ values of the $\mathrm{PVC} / \mathrm{G}-\mathrm{CaCO}_{3}$ and $\mathrm{PVC} / \mathrm{NG}-\mathrm{CaCO}_{3}$ composites, we can find that the $\mathrm{B}$ value of the $\mathrm{PVC} / \mathrm{NG}-\mathrm{CaCO}_{3}$ composites are larger than those of the $\mathrm{PVC} / \mathrm{G}-\mathrm{CaCO}{ }_{3}$ composites, that is, the interfacial adhesion strength between the $\mathrm{NG}-\mathrm{CaCO}_{3}$ particle and $\mathrm{PVC}$ matrix are larger than the one between the $\mathrm{G}-\mathrm{CaCO}_{3}$ particle and $\mathrm{PVC}$ matrix.

The interfacial morphology between the inorganic particle and the polymer matrix is one of the facts affecting the tensile strength and elastic module of the polymer composites. To improve the interfacial morphology, especially enhance the interfacial adhesion strength, can increases the tensile properties of the polymer composites.[11] Comparative the analysis of the data in Table $1,2,3,4$ and 5, we know that the larger the B is, the stronger the interfacial adhesion strength is, and the better the tensile properties is.

Table 5 the interfacial interaction strength of the $\mathrm{PVC} / \mathrm{CaCO}{ }_{3}$ composites

\begin{tabular}{ccccccccc}
\hline Materials & \multicolumn{2}{c}{$\mathrm{PVC} / \mathrm{P}-\mathrm{CaCO}_{3}$} & \multicolumn{2}{c}{$\mathrm{PVC} / \mathrm{G}-\mathrm{CaCO}_{3}$} & \multicolumn{2}{c}{$\mathrm{PVC} / \mathrm{NG}-\mathrm{CaCO}_{3}$} & \multicolumn{2}{c}{$\mathrm{PVC} / \mathrm{N}-\mathrm{CaCO}_{3}$} \\
\hline Modification or not & no & yes & no & yes & no & yes & no & yes \\
$B$ & 2.98 & 3.14 & 3.12 & 3.15 & 3.15 & 3.17 & 4.82 & 5.44 \\
\hline
\end{tabular}

\section{Conclusion}

After modification, the tensile properties of $\mathrm{PVC} / \mathrm{CaCO}_{3}$ composites was improved, the $\mathrm{PVC} / \mathrm{P}-\mathrm{CaCO}_{3}$ composite has the maximum growth rate in tensile strength and tensile elastic module, the $\mathrm{PVC} / \mathrm{P}-\mathrm{CaCO}_{3}$ composite has the maximum growth rate in elongation at break. Under the same modification conditions, the $\mathrm{PVC} / \mathrm{N}-\mathrm{CaCO}_{3}$ had the maximum tensile strength and elongation at break, the PVC/P-CaCO 3 composite had the maximum tensile elastic module. The interfacial adhesion strength between the $\mathrm{CaCO}_{3}$ particle and $\mathrm{PVC}$ matrix increased, and the tensile 
properties of the $\mathrm{PVC} / \mathrm{CaCO}_{3}$ composites were improved. The interfacial adhesion strength of the $\mathrm{PVC} / \mathrm{NG}-\mathrm{CaCO}_{3}$ composite was larger than that of $\mathrm{PVC} / \mathrm{G}-\mathrm{CaCO}_{3}$ composite.

\section{References}

[1]S. Yang, H. Qiu, B. Cheng, etc. Research on PVC/CB/Cu Plating Graphite Nanosheets Electrical Conductive Poly (vinyl chloride) Composites Filled with Mixed Filler, [J]. China Plastics, 2014(9): 12-18.

[2] M.L. Xin, H.Y. Lin, M.D. Li, etc, Research Progress and Lifetime Assessment of PVC Pipe, [J]. Plastics Science and Technology, 2015, 43(8):95-98.

[3] Z.D. Zhang, X.M. Chen, Y. Dong, etc. Nana-CaCO3 filled powdered rubber composite particles reinforcing and toughening polyvinyl chloride, [J]. Acta Materiae Compositae Sinica, 2012, 29(6): 19-25.

[4] P.P. Zhou, Y.H. Luan, X.S. Ma, Study on Synthesis of Surface Modifier of Calcium Carbonate And Its Application to PVC, [J]. CHINA PLASTICS INDUSTRY, 2013, 41(9): 39-43.

[5] M.M. Lang, Y.H. Jiao, J.X. Xie, etc. Preparation of Calcium Carbonate by Biomimetic Synthesis and Its Application in PVC,[J]. Plastics Science and Technology, 2010,38(10): 77-80.

[6] A. Abd. Studying the mechanical and electrical properties of epoxy with PVC and calcium carbonate filler, [J]. International Journal of Engineering and Technology, 2014, 3(4):545-553.

[7] Y.H. Jiao, F. Peng, J.Z. Xu, etc, Biomimetic synthesis of zinc hydroxylstannate-coated calcium carbonate and its application in PVC, [J]. Chemical engineer, 2011(5):227-280.

[8] B. Turcsanyi, B. Pukanszky, F. Tudos, Compositiondependence of tensile yield stress in filled polymers, [J].Journal of Materials Science Letters, 1988, 7: 160-162.Polymer Science, 1988, 35: 549-561.

[9] C.B. Wu, Study on Quantitative Characterization for Bond Strength of Diatomite Filled Polypropylene Composite, [J]. Plastics Science and Technology, 2010, 38(1): 46-49.

[10] C.B. Wu,J.Z. Liang, Contrast Study on Two Parameters for Characterizing Interfacial Interaction Strength of Inorganic Particle Filled Polymer Composites, [J]. Plastics Science and Technology, 2015, 43(5): 38-42.

[11] C.B. Wu, Mechanical Properties and Fractal Characterization on the Impact Fracture Surface of Polypropylene/Inorganic Particulate Composites, [D]. Guangzhou,South China University of Technology, 2009. 